\title{
Productive Uncertainty and Postpedagogical Practice in First-Year Writing
}

\author{
Megan McIntyre* \\ $06 / 20 / 2018^{\dagger}$
}

\begin{abstract}
To succeed beyond the writing classroom, students need creative thinking and adaptable, transferable writing and learning strategies, both of which are emphasized by a classroom approach called "postpedagogy." Postpedagogy emphasizes experimentation and reflection as integral to composing processes, especially digital composing. One feature of postpedagogical classrooms is writing assignments that require students to make a broader range of rhetorical choices and experiment with new approaches, audiences, mediums, and/or technologies. I offer my "definitional text" assignment as an example of one such writing assignment. Though the experimentation encouraged by postpedagogical approaches may lead to initial failures and frustration, such failure can be made productive via intensive, sustained, and specific reflection on composing and learning processes.
\end{abstract}

\section{Introduction}

Confusion, frustration, and failure can teach in ways that cannot be duplicated by other methods. These are often the necessary conditions for innovation and adaptation. To get from failure and confusion to innovation and adaptation, our classrooms must make space and invent situations that encourage - even require - students to try something new. By pairing new mediums and genres with open-ended assignments, I ask student to make decisions about expectations and audiences and adapt familiar tools and approaches for new (and sometimes unintended) purposes. Or, if familiar tools or approaches prove insufficient, students must take a leap and learn to use new tools. I refer to this as creative problem solving. Almost inevitably, this kind of experimentation with unfamiliar

\footnotetext{
*Department of English, Sonoma State University, meg.m.mcintyre@gmail.com. Copyright 2018 Megan McIntyre. This work is licensed under a Creative Commons Attribution-NonCommercial 4.0 International License (http://creativecommons.org/licenses/by-nc/4.0/).

${ }^{\dagger}$ Submitted,01/31/2017; Accepted, 02/14/2018.
} 
ideas, tools, and methods leads students - at least initially - to fail. To navigate this (often unfamiliar) failure, systematic, specific reflection is necessary; such reflection helps students adapt in the face of that failure. This approach to teaching and learningexperimentation, failure, reflection, adaptation - fits into "postpedagogy," a term coined by Gregory Ulmer in the 1980s and adapted and extended by teacher-scholars like Thomas Rickert, Sarah Arroyo, Marc Santos, and Jody Shipka, though the latter has not adopted the label. Postpedagogy recognizes the value of experimentation. A postpedagogical classroom opens space for student innovation, creative thinking, and creative problem solving through writing assignments that offer fewer constraints and encourage studentwriters to explore new mediums and genres; postpedagogy also posits assessment practices that de-center teachers in favor of allowing students to co-create guidelines, boundaries, and even grading criteria and practices (McIntyre, 2016; Santos \& McIntyre, 2016).

Some will likely argue that the practices described here are widely accepted in particular parts of rhetoric and composition, broadly conceived. They are right. Within digital rhetorics and multimedia/multimodal composition, in particular, many of these pedagogical orientations are widely accepted practices. The kind of postpedagogy I advocate here distinguishes itself in a few particular ways. First, though this emphasis on cocreation of classroom experience is a feature of much of critical pedagogy, postpedagogy eschews critique as its primary mode of engagement; critique is replaced by creation and experimentation as the primary focus of the classroom. Second, though the project I describe later is multimodal, the postpedagogical approach I outline here need not be confined to the digital rhetorics classroom nor to multimodal/multimedia projects. Instead, the sequence of practices - experimentation, failure, reflection, adaptation - also has applications in more traditional academic mediums. Beginning from a point of creation/experimentation and moving through challenges via reflective practice allows students to strategically adapt writing and learning approaches across time, space, and medium.

In what follows, I point to research that confirms the value of creative thinking, offer an assignment that seeks to encourage productive confusion via experimentation and reflection, and discuss the challenges and possibilities opened by this assignment.

\section{Making Space for Creative Thinking}

It is not just my classroom experience and my belief in the value of postpedagogical approaches that leads me to value confusion, failure, and innovation; I value this approach because these experiences open spaces for students to think critically and invent or adapt new, innovative approaches to questions and problems across contexts. The literature on transfer suggests that providing opportunities to innovate and take risks helps build the student self-efficacy that contributes to transfer across writing and learning contexts, especially when those experiences include thoughtful reflection (Abrami \& Barrett, 2005; Nicolaidou, 2012; Walker, 2003; Zimmerman, 2000). Especially in situations that demand not just transfer but transformation of knowledge, students need a "meta-awareness" 
of how genres operate (DePalma, 2015). Asking students to make decisions about approaches, audiences, mediums, and/or technologies requires them to develop this sort of awareness.

Beyond the value of writing knowledge transfer and adaptation in academic contexts, critical thinking and creative problem solving are also among the qualities most coveted by employers. A 2013 survey by the American Association of Colleges and Universities (AACU) found that a staggering $93 \%$ of employers surveyed agreed that "a demonstrated capacity to think critically, communicate clearly, and solve complex problems is more important than [a candidate's] undergraduate major." Of those surveyed, $75 \%$ also called for increased attention to "five key areas including: critical thinking, complex problem solving, [and] written and oral communication." Furthermore, it has become a fairly common practice, especially in the tech sector, to pair programmers and engineers with people with backgrounds in the arts, liberal arts, humanities, and social sciences to create more innovative and user-friendly products and environments (Anders, 2017; Henseler, 2014; Segran, 2014).

Slack (a cloud-based site that facilitates teamwork and collaboration) exemplifies such values. As George Anders notes in his 2015 profile of the company, Slack's cofounder and CEO, Stewart Butterfield, holds degrees not in computer science or another technological field but in philosophy. His background in the liberal arts has been, Anders suggests, at least part of the reason for Slack's success: "Hard-core engineers have been trying to build knowledge-management software for at least 15 years. Most of their approaches are so cumbersome that corporate users can't wait to quit. Slack makes everything simple" (Anders, 2017). Engineers, by training, are often creative and critical problem solvers because engineering curricula emphasizes the need for multiple approaches and multiple possible solutions (Daly, Mosyjowski, \& Seifert, 2014; Dewulf \& Baillie, 1999; Stouffer, Russell, \& Oliva, 2004). Pairing these often-innovative thinkers with partners in the humanities allows the team to better represent a diverse user base and translate technologically complex problems and solutions into spaces navigable by a wider variety of users, including novice users.

And Slack is not alone: in their book The Second Machine Age, Erik Brynjolfsson and Andrew McAfee (2014) argue that the increasing relevance and ubiquity of technology has already begun to inspire a model of task management in which technologies increasingly complete mundane and routine tasks. As Slack's success reveals, though, creating technologies that can be easily integrated into human lives requires more than great code; it requires the kind of creative thinking emphasized by - though, as noted above, by no means exclusive to - work in the humanities.

\section{Postpedagogy in Practice: Definitional Text Assignment}

Creative thinking and rhetorical flexibility (the ability to consider audience, purpose, and medium and then use that information to adapt to new or experimental communication 
situations) can be encouraged in any number of ways, including through the study and analysis of literature and artwork, through hands-on work in the creative arts, and through fieldwork in the social sciences. It can also be encouraged, I have found, through writing assignments that require students to move beyond more comfortable genres, approaches, and writing tools and then to reflect on their choices and experiences.

The most recent iteration of my definitional text assignment appeared in a first-year writing course; the cap is 16 , and since this a required course and must be taken in the first year, the class is almost always full. My first-year writing program operates from a set of faculty-created shared outcomes, but faculty choose their own themes, genres, projects, and assignments. My class includes three major projects with multiple drafts of each project. By the time students begin the project under discussion here, they have already completed two major, research-based projects in the course. We begin with a literature review essay that segues into a case study project on the same or a related topic. Because our terms are only 10 weeks long, this scaffolding makes both pedagogical and practical sense. As a class, we spend the six to seven weeks leading up to the definitional text assignment talking about the rhetorical foundations of writing, research approaches and resources, source credibility, and audience, in addition to discussing reading related to our course topic. The definitional text assignment asks students to choose a term that has become important during their research and writing process over for the first two projects, create their own definition of that term, compose a text that contains fewer than 300 written words to communicate that definition to an audience of their choosing, and draft a reflective cover letter that discusses their choice and processes. There are no constraints in terms of what term they choose to define, what audience they target, or what medium they utilize.

I assign this project for a few reasons. First, throughout their research projects, most students encounter texts that use key terms in wildly different ways; this project provides students the opportunity to grapple with those sometimes conflicting usages. Second, multimodal composition is a vital part of learning to compose in the college context; this project allows students to think through (and allows me to assign readings and lead discussions about) how medium and message affect one another. Finally, this project allows me to reinforce the kind of reflection that is a cornerstone of the class. For the definitional text assignment, this reflection takes multiple forms over the course of the project: students compose proposals, revision plans, cover letters for later drafts, and project postmortem ${ }^{1}$ surveys so that, at each step of the process, they can consider their composing choices and the relative success of each of those decisions.

Though I am happy to work with students to explore digital tools and potential new genres, I resist providing examples until students have drafted a significant portion of their texts and begun work on their cover letters. Too often, I have found, students rely on examples as a set of constraints rather than an incomplete set of possible approaches. Because my goal is for students to explore new spaces, tools, and literacies, I want to limit the constraints at the beginning of the project and instead encourage them to pursue a project that is interesting or exciting to them, even if they are not quite sure if 
it will work. This approach is sometimes challenging for students, as unfamiliarity can result in initial failures; the number of students whose projects change drastically from proposal to final submission is comparatively quite high. For the research projects that precede the definitional text project, students' project proposals mostly match their final drafts; on average, only one or two students make a radical change in terms of research question or general approach. For this project, on the other hand, nearly half of students make radical, significant changes to their projects at some stage of the process. Their full drafts look quite different than their proposals, and/or their final drafts look quite different than their full drafts.

These choices and changes happen in response to feedback from me and from their peers, but they also happen when students discover that their first forays into a new genre or reaching an unfamiliar audience simply do not work the way they imagined. The students in my course have, by and large, been unacquainted with assignments that lack specific genre and audience expectations; the need to make such decisions for themselves can be exciting for some, but, for many, fear of failure overwhelms such freedom. To help students move past that fear or their initial failures, I build in multiple opportunities for reflection, including in one-on-one conferences, low-stakes daily reflective posts, revision plans, and self-assessments. Reflection is a necessary part of this process, and it must happen early, often, and in a variety of forms. These reflective opportunities allow students to assess their choices, consider their successes, name their failures, and make plans to move forward. Such reflection also encourages students to think beyond our course or their assumptions about writing classes to consider how outside interests, other courses, and previous learning experiences might provide new avenues to explore.

As students work their way through their composing processes, they often find inspiration in disparate experiences beyond our classroom. In my Fall 2016 course, for example, a student who was also taking a computer science course coded a quiz/website meant to help readers distinguish white hat, gray hat, and black hat hacking. The quiz posed scenarios and asked the quiz-taker to classify the kind of hacker who might undertake the given endeavor. After each answer, the creator provided parts of his definition and worked to provide nuance to his seemingly fixed categories. As he notes, "At first glance, the definitions I present seem straightforward, but the lines between them become much more blurred when they have to be applied to specific situations." He chose his medium because he felt that the digital quiz format offered him the best opportunity "to interact with the user." Another student in the same course chose to use the animation generator Powtoon to offer a definition of the term hacktivism via cartoon "training video." The student chose this format, he said, because the low-resolution version of his video can easily be "shared on a number of mediums," particularly social media, where he feels he can best reach his audience of "grey hat hackers," because he wants "to persuade these somewhat undecided hackers to use their skills to enact positive change in the world." Other students have made Prezis (to define cryptocurrency and ambiguity) and wanted posters (to define Anonymous), podcasts (to define encryption and catfishing) and graphic novels (to define lulz), Twitter bots (to define fake news), and interview 
videos (to define technology).

These examples are, however, the result of a challenging process. The initial response to this assignment is often one of bewilderment. Students find the language of the assignment clear enough: make something that offers a definition and then tell me what you made and why. What troubles students, as I note above, is the lack of constraints or specific instructions about how best to accomplish this goal. Without the safety net of established academic genres and practices, students often fear that either I have some (invisible, unarticulated) ideal text or that, should they try a new approaches, audiences, mediums, and/or technologies, and not successfully fulfill their vision for the project, their grade in my class will suffer irreparable harm. I do not wish to downplay these fears; grades matter. I seek to address these fears in two ways. First, the cover letter portion of the assignment intentionally provides students space to articulate their own learning even if that learning does not result in a fully successful project. Second, as I do with every project in our course, I work with students to create the grading criteria for this project. Though some of those criteria are indicated by the assignment itself, most of the guidelines I follow when grading these projects are invented by the class via a collaborative, ongoing discussion over the life of the project. In past terms, these criteria have included "production quality (looks like you've put time and effort and thought into the aesthetics)" and "articulated challenges (cover letter describes what went wrong, how you responded, and what you might need to learn to be more successful next time)."

\section{Challenges: Confusion, Fear, and Assessment}

This assignment seeks to encourage students to move beyond the genres and tools they know well, and then reflect on their choices and challenges. It is an assignment I have used in first-year composition (the context of the specific assignment above), advanced composition courses, and professional writing courses. And, though I have not yet conducted specific research in the first-year composition context, some preliminary research from my courses in advanced composition for professional writing majors suggests the assignment does result in the kind of creative problem solving emphasized above. In 2014, a fellow postpedagogue and I conducted an IRB-approved examination of student postmortem reflections on each of the projects in two upper-division courses for technical and professional writing majors. As part of my course, students received a definitional text assignment almost identical to the one above. After completing the project, I asked students to consider any number of dimensions of their projects and creative processes, including "What is one literacy, approach, or piece of knowledge you feel you gained from this project?" Without specific prompting, 6 of 16 students noted that the project gave them insight into the value of understanding audience and/or purpose when making decisions about form and content and another four students felt the project taught them that reflection is an important part of the creative process.

Not all students find the process enjoyable, however: the same study, conducted across two courses using similarly unconstrained assignments, found that 29 of the 30 students 
who responded to an anonymous, end-of-term survey regarding their experiences in our postpedagogical classrooms confirmed that at some point during the composing process, they felt frustration, anxiety, and/or confusion. In response to these students (and to teachers wary of this kind of assignment), I wish to emphasize three related things. First, using this kind of assignment (and creating a postpedagogical classroom in general) requires a significant degree of trust from students. I seek to build this trust throughout the term by meeting one-on-one with students for each project and by being as transparent as possible about the reasons for assigning such a project. Second, including students in the development of grading criteria is particularly important in building trust with my students. By creating the criteria with them, I can avoid the appearance that I have some perfect project in mind but am withholding the details from them. When we create the criteria together, students have a significant say in what the standards are and how they can meet these standards. Finally, reflecting on this assignment is as important (if not more important) than creating a successful definitional text. Many students eventually find their way to something fundamentally productive. As one student commented, "I was lost, but not for long. As soon as I became actively engaged in the project, I started to find solutions. And each answer found spurred a bunch of ideas to follow." Getting to this point, however, requires significant and ongoing reflection. Students in the upper division course for technical and professional writing majors answered reflective questions after each of the major projects and completed an end-of-term reflective assignment that asked them to consider how their processes shifted over the course of the term. Similarly, in the first-year writing course in which the above writing assignment appears, students craft revision plans after the first round of feedback from their peers and me and compose short, twice-weekly reflection posts. Students also craft a reflective cover letter for each of their final drafts, and they complete an end-of-term portfolio with an essay that discusses the literacies and strategies they have developed over the course of the term. Reflection, then, is specific, recursive, and developmental. These three things represent best practices in postpedagogy: find ways to build trust, give students significant input into the grading process, and build in specific, sustained reflection at multiple points in the process.

\section{Conclusion}

As the AACU study indicates, student success beyond the college classroom increasingly depends on students' ability to innovate and adapt to new learning and working environments. Within writing studies, literature on knowledge transfer and adaptation suggests that reflection encourages students to transfer and adapt knowledge across writing and learning contexts (Alexander \& Murphy, 1999; Wardle, 2007); such reflection might also improve students' ability to transfer writing knowledge across disciplinary contexts (Ford, 2004; Schieber, 2016). Less detailed assignments, ones that require students to make explicit decisions about approaches, audiences, mediums, and/or technologies and then to specifically articulate their decision-making process and defend their choices, ask students to develop both the kind of creative thinking coveted by future employers 
and the reflective impulses that encourage knowledge transfer and adaptation in new, unfamiliar, and emerging writing and learning contexts.

\section{Assignment}

See the Supplementary Files for this article at thepromptjournal.com for a PDF facsimile of the original formatting of this assignment.

For our final project, you will choose and define a term that seems vital to your understanding of our course content. This definition may take nearly any form you like except one: you may not compose a traditional essay for this project. In fact, you may use no more than 300 written words in the final draft of this project. You may, however, use as many spoken words, images, video clips, etc. as you like (within fair-use guidelines and in accordance with copyright law). Since there is no minimum written word count for this project, you will be evaluated instead based on three criteria: (1) how well you employ the medium/form you chose to convey your message, (2) how well you utilize evidence that is appropriate for the medium/form and persuasive to your chosen audience, and (3) how well you articulate your rhetorical choices for the project. In order to address these criteria, you will compose a project cover letter (of at least 1500 words), addressed to me, that introduces your definitional project and speaks to these three criteria. You will revise your project draft at least twice in response to feedback from me and from your peers.

\section{Notes}

\footnotetext{
${ }^{1}$ Postmortem here refers to the practice, in video game design and other creative enterprises, in which members of the production team meet after a product launch to frankly discuss failures and make plans to ameliorate those failures in future projects. It is a particular kind of reflective practice characterized by an emphasis on articulating challenges and establishing new or better practices in response to those challenges and failures.
}

\section{References}

Abrami, P., \& Barrett, H. (2005). Directions for research and development on electronic portfolios. Canadian Journal of Learning and Technology, 31 (3).

Alexander, P. A., \& Murphy, P. K. (1999). Nurturing the seeds of transfer: A domainspecific perspective. International Journal of Educational Research, 31(7), 561-576.

Anders, G. (2017). That 'useless' liberal arts degree has become tech's hottest ticket. 
Forbes. Retrieved from http://www.forbes.com/sites/georgeanders/2015/07/29/liberalarts-degree-tech/\#164084775a75

Brynjolfsson, E., \& McAfee, A. (2014). The second machine age: Work, progress, and prosperity in a time of brilliant technologies. New York, NY: WW Norton \& Company.

Daly, S. R., Mosyjowski, E. A., \& Seifert, C. M. (2014). Teaching creativity in engineering courses. Journal of Engineering Education, 103(3), 417-449.

DePalma, M.-J. (2015). Tracing transfer across media: Investigating writers' perceptions of cross-contextual and rhetorical reshaping in processes of remediation. College Composition and Communication, 66(4), 615.

Dewulf, S., \& Baillie, C. (1999). CASE: Creativity in Art, Science and Engineering: How to foster creativity. London, UK: Great Britain Department for Education and Employment.

Ford, J. D. (2004). Knowledge transfer across disciplines: Tracking rhetorical strategies from a technical communication classroom to an engineering classroom. IEEE Transactions on Professional Communication, 47(4), 301-315.

Henseler, C. (2014). A surprising success story: Jobs and the arts and humanities. Huffington Post. Retrieved from http://www.huffingtonpost.com/christine-henseler/asurprising-success-stor_b_5669505.html

McIntyre, M. M. (2016). Reflection, detours, and postpedagogical practice. Textshop Experiments, 2. Retrieved from http://textshopexperiments.org/textshop02/reflectiondetours-and-postpedagogical-practice

Nicolaidou, I. (2012). Can process portfolios affect students' writing self-efficacy? International Journal of Educational Research, 56, 10-22.

Santos, M., \& McIntyre, M. M. (2016). Toward a technical communication made whole: Disequilibrium, creativity, and postpedagogy. Composition Forum, 33. Retrieved from http://compositionforum.com/issue/33/techcomm.php

Schieber, D. L. (2016). Invisible transfer: An unexpected finding in the pursuit of transfer. Business and Professional Communication Quarterly, 79(4), 464-486.

Segran, E. (2014). Why top tech CEOs want employees with liberal arts degrees. Fast Company. Retrieved from https://www.fastcompany.com/3034947/the-future-ofwork/why-top-tech-ceos-want-employees-with-liberal-arts-degrees

Stouffer, W., Russell, J. S., \& Oliva, M. G. (2004). Making the strange familiar: Creativity and the future of engineering education. In Proceedings of the 2004 American Society for Engineering Education Annual Conference 83 Exposition.

Walker, B. J. (2003). The cultivation of student self-efficacy in reading and writing. 
Reading 83 Writing Quarterly, $19(2), 173-187$.

Wardle, E. (2007). Understanding "transfer" from FYC: Preliminary results of a longitudinal study. Writing Program Administration, 31(1-2), 65-85.

Zimmerman, B. J. (2000). Self-efficacy: An essential motive to learn. Contemporary Educational Psychology, 25(1), 82-91. 